\title{
SALIR DE LAS TRINCHERAS. PERIODISMO Y RADICALIZACIÓN POLÍTICA DURANTE LOS MIL DÍAS
}

Antoine Faure 


\section{ANTOINE FAURE}

Doctor en Ciencia Política de Sciences Po Grenoble (Francia). Profesor asistente de la Escuela de Periodismo de la Usach. Sus áreas de especialización son las dimensiones políticas de las temporalidades comunicacionales (periodismo y series de televisión) y las dimensiones temporales de lo político (movimientos sociales y acción pública), a partir de un enfoque sociohistórico. 


\section{SALIR DE LAS TRINCHERAS. PERIODISMO Y RADICALIZACIÓN POLÍTICA DURANTE LOS MIL DÍAS ${ }^{1}$}

Chile vive un periodo social y político agitado, que se intensificó a partir del 18 de octubre de 2019. Origina, construye y provoca un nuevo hito con el plebiscito nacional del 25 octubre de 2020, que implicaría reemplazar la Constitución ilegítima de 1980 por una nueva a partir de un proceso constituyente. En un contexto de tensión política, es interesante constatar el (ab)uso de ciertas memorias vinculadas a la Unidad Popular (UP) que desarrollan analogías con el gobierno de Allende con el fin de dotar de sentido distintas posiciones y acciones políticas. Las similitudes residirían, según numerosas voces, tanto periodísticas como políticas o académicas, en la polarización y la radicalización política de la sociedad. La amenaza sobre el proceso contemporáneo replica la demonización de la política como un potencial caos, cuyos responsables fueron, durante la UP, los "pilares" de la democracia liberal: la prensa y la política, en tanto poder y espacio de participación.

En este contexto, se repiten en 2020 múltiples y repetidas agresiones y amenazas en contra de periodistas nacionales e internacionales en Chile. Estas reactivan el recuerdo de los primeros años después del fin de la dictadura y el mismo periodo del régimen autoritario. A la vez, las amenazas políticas hacia profesionales del periodismo que cubren las movilizaciones sociales también se han comparado con la batalla mediática y la prensa de trinchera que, comúnmente, actualizan el recuerdo y el conocimiento sobre el periodismo durante la UP. En este sentido, se tiende a confundir la politicidad del quehacer periodístico con su politización, a través de una "llamada al orden" cuando los medios de comunicación se ven tensionados por el contexto histórico y se desplazan las fronteras de la profesión.

Por esta razón, es fundamental interrogar (de nuevo) el ejercicio del periodismo en Chile entre 1970 y 1973, para tomar distancia de estas representaciones maniqueas, superar miradas revisionistas de la historia y construir una democracia donde la prensa pueda cumplir su rol político sin ser acusada de derivas ideológicas. Más que ideologizar todos los contenidos y los medios, la politización de la sociedad chilena ejerció una fuerte presión temporal sobre el proceso de producción de las noticias,

1. Este ensayo forma parte del proyecto FONDECYT de Iniciación 11170348 "Historia de las temporalidades periodísticas chilenas (1973-2013): otra mirada sobre la dimensión política del periodismo profesional” (2017-2020). Agradezco a Carla Rivera (UsACH) por sus inestimables comentarios a este texto. 
hasta provocar cambios organizacionales que se reflejan en la materialidad de los medios de comunicación y ponen en evidencia la transformación de las normas profesionales y de la figura social del "periodista". Presionado por la competición política, la urgencia de los acontecimientos, así como por las experiencias comunicacionales y periodísticas alternativas, el quehacer periodístico chileno pasa de rellenar el espacio del diario a alimentar un flujo acelerado de noticias. Este proceso cambia el sentido mismo de la noticiabilidad, es decir, el valor de la información a los ojos del periodista (Gans, 1980; Tuchman, 1978), ya que la prioridad se vuelve el flujo de noticias por sobre el filtrado. Se trata de una transformación, porque existiría una posible continuidad de esta nueva manera de pensar y ejercer el periodismo en los años posteriores al golpe de Estado de 1973 y hasta el presente.

Proponemos, entonces, contrastar la tesis de la ideologización del periodismo durante contextos de radicalización política para tomar en serio la siguiente hipótesis: los mil días serían un momento culminante de la reorganización de las rutinas y de las prioridades del quehacer periodístico, según una lógica profesional antes que política. Es decir, se propone que la politización de la sociedad chilena durante la Unidad Popular no habría generado una distorsión ideológica en las rutinas periodísticas profesionales ni los periodistas se habrían convertido exclusivamente en militantes de partidos políticos. Sin duda, existe una radicalización de las líneas editoriales de la prensa chilena durante la UP. Sin embargo, esta explicación dice más sobre la relación histórica de la sociedad chilena con los mil días de Allende que sobre el periodismo en el contexto de radicalización política propio del periodo 1970-1973.

Esta hipótesis plantea una pregunta aguda, con fuerte eco en el presente, porque cuestiona el uso de la categoría analítica de pluralismo para diferenciar los regímenes políticos al plantear continuidades periodísticas entre democracia y dictadura, no obstante las condiciones diametralmente opuestas de libertad de prensa y de expresión. Sin entrar en los largos debates sobre esta noción, se evidencia en nuestra investigación que las condiciones de pluralismo no son un factor relevante para comprender las transformaciones del periodismo en la historia chilena reciente. Por el contrario, las transformaciones del oficio no siguen, en Chile, la cronología de los regímenes políticos.

\section{ACTUALIZACIONES}

La Unidad Popular aún vive en nuestro presente. Se actualiza en cada conmemoración. Se disputa en cada relato sobre los mil días y los 17 años de autoritarismo que le siguen. El golpe de Estado, sin duda, es la bisagra, el filtro histórico para leer los dos periodos. La pregunta sobre lo que ha provocado la intervención militar y la 
instalación del régimen autoritario ha monopolizado muchas discusiones. Bien lo muestran las vivas controversias sobre la necesidad de incluir (o no) al gobierno de Allende en la museografía del Museo de la Memoria y los Derechos Humanos.

Dentro de estos debates, las prácticas orales y textuales que se experimentaron durante la UP han sido ampliamente estudiadas y recordadas. En lo que respecta a los medios, la reflexión tuvo dos ejes: uno giró en torno a las diferentes dimensiones de la ideología burguesa que la "objetividad periodística" transmitía (en orden alfabético y entre otros, Catalán, 1967; Durán, 1994 [1973]; Fadden, 1974; Lagos, 1962; Mattelart y Mattelart, 1972, 1974; Taufic, 2012 [1971]); otro, del lado más conservador, se dirigía a las condiciones de la libertad de expresión en un proyecto socialista (MacHale, 1972).

Se perpetuó el estudio del problema después de la "vía chilena al socialismo" (según la formulación consagrada), pero se planteó otra pregunta: ¿en qué medida el trabajo mediático había contribuido a radicalizar el conflicto político para orientar el cambio social hacia una democracia socialista? Entre expiación de culpas, heroísmo nostálgico y una historia planteada desde el golpe de Estado, historia y memoria buscan y observan exclusivamente el periodismo de trinchera, lo que da una representación histórica parcial del ejercicio del periodismo durante la UP. Finalmente, las comunicaciones y el periodismo se han consolidado como problema, en un esfuerzo académico para sintetizar la batalla mediática que, según la gran mayoría de los autores, ha ocurrido entre 1970 y 1973 (Alvear y Lugo-Ocando, 2016; Bernedo, 2003; Bernedo y Porath, 2003-2004; Cárdenas, 2005; Dooner, 1989; Joignant, 2012; Portales, 1983; Rojo de la Rosa, 1976; Santa Cruz, 1988; Sunkel, 1985; Tironi y Sunkel, 1993; Tupper, 2004; Uribe, 1996).

La memoria de la profesión también propone una lectura que privilegia la variable política para explicar las derivas y exageraciones que se cometieron durante la Unidad Popular (Baltra, 2014; Cárdenas, 2005; Navarro, 2013). Se pone en evidencia, en los testimonios tanto escritos como orales, una simetría entre el campo periodístico y el campo político: como si una politización extrema llevase la inestabilidad a todos los campos sociales de manera sistemática.

En un trabajo de entrevistas en profundidad que realizamos entre 2007 y 2011, se evidencia la fuerza del discurso sobre la "prensa de trinchera" en la misma estructura de las entrevistas. Al mencionar el tema de la investigación o al preguntar por el trabajo periodístico durante la UP, los periodistas siempre abordaban primero el conflicto mediático desde la batalla política. Ya fuera para visibilizar las derivas e ilusiones del momento o para recordar con nostalgia un tiempo politizado donde la profesión tenía otro sentido, una responsabilidad social. De manera común a los dos puntos de vista, los/as entrevistados/as usan en numerosas oportunidades expresiones como "prensa de trinchera" o "periodismo de trinchera". Se verbaliza como una especie de sentido común sin cuestionar. 
De la misma manera que las conmemoraciones y homenajes a las figuras detenidas desaparecidas de la profesión, estos relatos a la vez individuales y colectivos sondean las responsabilidades periodísticas en la crisis política de la sociedad chilena entre 1970 y 1973, y las repercusiones que vivieron la comunidad y sus miembros durante el régimen autoritario. Leen la historia desde su resultado (el golpe de Estado), como si todo hubiese ocurrido según este inevitable desenlace.

El contexto de expresión muestra el profundo anclaje del discurso sobre la profesión durante los mil días. Parece que la mirada se ha arraigado en el tiempo, desde los primeros años del régimen autoritario hasta el Chile postdictatorial. Sin embargo, cada uno de estos relatos actualiza el discurso sobre el periodismo durante la UP — y sobre los mil días en general—. Sedimentan parte de las representaciones que circulan sobre el periodo y agregan nuevas maneras de comprenderlo, que dicen más sobre el momento en el que se emiten estos relatos que sobre el periodismo durante el gobierno de Allende.

Este discurso, tanto historiográfico como memorial, se confunde, en cierta medida, con las justificaciones aportadas por las élites cívico-militares para cerrar y expropiar las empresas mediáticas, reprimir y censurar, lo que se sostuvo en una entidad estatal controladora y provocó la autocensura. Si bien después de 1976 las revistas de oposición circulan de nuevo, entre un fuerte simulacro de objetividad y una posición democrática (Rivera, 2008), la memoria sobre lo que ha sido el periodismo antes (del golpe) sigue consolidando el relato de excesos, derivas y polarización.

A orillas de los años noventa, este mismo discurso ha legitimado el lugar del periodismo en el proceso de reconstrucción del régimen democrático. Se usa como argumento para defender la regulación del sistema de comunicación por el mercado, y traza la norma regulando el "buen periodismo", es decir, los límites de la mediación periodística entre ciudadanía y poderes públicos y privados. El lugar del periodismo y la norma de esta mediación consisten en evitar instalar de nuevo condiciones políticas como las de 1973, específicamente, en neutralizar las presiones partidarias sobre la profesión.

Así, en la concepción misma del proyecto democrático, tecnificado y orientado hacia la estabilidad política, se norma el periodismo detrás de un dique: evitar a toda costa su politización. Las discusiones de la Comisión Constitucional de 1980 bien revelan cómo la profesión está asimilada a su función ideológica (Ahumada, 2017) y la Constitución, pensada para contener lo que se considera como inevitables derivas políticas de parte de los medios de comunicación. Mientras la segunda fase del régimen autoritario había sido el escenario de una batalla comunicacional y política, apenas se reorganiza la democracia se refuerza la mediación del sistema mediático por el mercado (Tironi y Sunkel, 1993): "la mejor política de comunicación es no 
tener ninguna política de comunicación” (ni política pública ni ideología). Además de la privatización del sector, la consecuencia directa será, sin duda, la desaparición de numerosas revistas, diarios y radios, además de la precarización de las condiciones de trabajo de los periodistas, así como el debilitamiento de las instancias corporativas y sindicales.

De manera coherente, la organización del campo ha sido desregulada. El Colegio de Periodistas retomó sus actividades en 1981, asumiendo la lucha por la libertad de prensa durante el periodo autoritario, pero ya no tiene la capacidad de regular las fronteras del campo. Conserva la autoridad de excluir a los periodistas a través de su Tribunal de Ética (función que guarda hasta hoy), sin embargo, ni la formación universitaria ni la colegiación ni la obtención de la tarjeta de periodista permiten controlar el ejercicio de la profesión. Es más, las querellas y denuncias del gremio funcionan como declaraciones sin efecto ni performatividad.

Entre el final del régimen autoritario y los primeros años de la democracia pactada, la fuerza del discurso sobre las lecciones del pasado se rastrea en las mismas escuelas de periodismo. En distintos discursos a finales de los años ochenta e inicios de los años noventa, Silvia Pellegrini, entonces directora de la Escuela de Periodismo de la Pontificia Universidad Católica de Chile (PUC), hace uso del contraejemplo del pasado para promover un periodismo responsable, con fundamentos (universitarios) firmes, que impiden derivas políticas conocidas en el pasado reciente. La Escuela de Periodismo de la Universidad de Chile recién había abierto de nuevo su sede en calle Belgrado, con un proyecto de formación profesional que se enfocaba, claramente, en temáticas que evitaran toda postura política, como se puede observar en los primeros años de la revista institucional Comunicación y Medios, donde escriben los académicos de la Escuela.

Esta política no alcanzó a cerrar todos los espacios políticos de la profesión, pero ha construido la norma de un periodismo antipolítico, y sentó la legitimidad de los medios informativos y tradicionales sobre la base de prácticas-técnicas. Por lo tanto, el discurso sobre el pasado del periodismo chileno durante la UP ganaría alguna performatividad al contribuir a delimitar la autonomía, la libertad y el pluralismo a la salida del régimen autoritario (1973-1990).

Abordar el periodismo durante la Unidad Popular implica, entonces, cuestionar el conocimiento histórico y la memoria profesional sobre el periodo. Nos parece decisivo en el contextual actual, en el que, no obstante existen evidencias que matizan el argumento de la ideologización del periodismo a ultranza durante la UP, la sedimentación de este discurso sobre el pasado reciente de la profesión resurge en momentos de crisis social, como lo muestra parte de los acosos y agresiones que recibió gran cantidad de profesionales al cubrir la protesta social, la crisis pandémica, los enfrentamientos en La Araucanía o la campaña plebiscitaria de 
2020. De nuevo se amenaza a periodistas en Chile por una supuesta confusión entre opinión e información, por acusaciones de trabajo político - un otro, esta vez de influencia bolivariano-chavista y ya no soviético-, como antes, durante y después de la Unidad Popular. La táctica sigue siendo la misma: acusar a ciertos y ciertas periodistas de buscar desestabilizar el país y el pacto social por razones ideológicas.

Se abre una pregunta central para distinguir entre las distintas comprensiones del concepto de "ideología" al momento de analizar el periodismo y los medios de comunicación durante la Unidad Popular. En efecto, se ha estudiado principalmente la ideología partidista de los periodistas. Después del golpe de Estado, se ha problematizado el proceso de ideologización de las páginas de los diarios y la polarización mediática que reflejaría las tensiones políticas chilenas entre 1970 y 1973. A pesar de las diferencias en sus enfoques y métodos, estos estudios convergen en su capacidad de atribuir una función ideológica de vocero a los medios de comunicación. Las consecuencias de la propiedad de las empresas mediáticas están naturalizadas a través de su influencia y control sobre la opinión pública, articuladas en estrategias esencialmente ideológicas para poner en circulación diferentes títulos y garantizar la exposición mediática de las diferentes capas sociales.

En su gran mayoría, los textos se apoyan sobre una economía política del sistema mediático, que vincula partidos políticos y propiedad de los medios de comunicación, y evalúa la fuerza de circulación de los distintos medios. Y proponen, en varias oportunidades, una analogía con el siglo XIX, durante el cual la prensa se dedica a la disputa política (Baltra, 2014; Tironi y Sunkel, 1993). Además de funcionar a partir de un anacronismo sociopolítico, estas lecturas construyen los contenidos mediáticos de dos maneras. Por una parte, como espejo de los enfrentamientos políticos (carácter simbólico). Por otra parte, como el objeto de un control político que busca, por la manipulación de órganos mediáticos, difundir las representaciones del mundo y las ideologías que son subyacentes (carácter instrumental). Por el despliegue de una visión determinista de la historia, estos estudios muestran la inevitabilidad del golpe de Estado, asimilando la línea editorial de los productos mediáticos al trabajo periodístico de las salas de redacción.

Además de esta asimilación discutible, la reapropiación retrospectiva del problema periodístico durante la Unidad Popular deja de lado el debate sobre la ideología escondida en la objetividad periodística, debate en curso antes y durante la Unidad Popular (Rivera, 2015). Reinscribimos aquí el análisis en el problema comunicacional de la época. Claramente, la "ideología" de la prensa (y los medios) define el trabajo que hacen los medios liberales burgueses —en específico El Mercurio - para difundir su visión del mundo a través de formas presentadas como neutras y objetivas. Los estudios chilenos se concentran en articular economía política del sistema mediático y semiología de los mensajes (véase el famoso ejemplo 
del tratamiento de la Reforma Estudiantil de 1967 en los Cuadernos de la Realidad Naciona) para alimentar la teoría de la dependencia cultural y aplicarla al sistema mediático (Mattelart, Mattelart y Piccini, 1970).

Finalmente, existe una tercera acepción de ideología que se puede aplicar al periodismo durante la Unidad Popular. La organización rutinaria del proceso de producción de las noticias activa, según Tuchman (1978), una "ideología profesional" que se reproduce cotidianamente.

En términos prácticos, el profesionalismo procede del ritual de la objetividad (Tuchman, 1978), de múltiples presiones (desde la jerarquía hasta el mismo campo, pasando por las fuentes, cf. Shoemaker y Reese, 1991), funciona por plazos, es decir etapas y secuencias obligadas para garantizar la publicación del medio a la frecuencia definida, y opera una selección y jerarquización de las noticias (Gans, 1980). Este procedimiento altamente rutinizado y repetitivo, en términos tanto individuales como colectivos, determina la noticiabilidad, es decir, el valor de la información a los ojos del periodista (Gans, 1980; Tuchman, 1978).

En términos culturales, las rutinas periodísticas proceden de la promoción y la defensa de normas y valores compartidos por los periodistas profesionales; es decir, del discurso sobre el "buen periodismo" (Wolf, 1997). Se cultivan con la formación y la socialización del oficio (Breed, 1952). Son decisivamente reconocidas por el Estado de Compromiso Social al momento de negociar una responsabilidad social y conceder, a cambio, la autonomía y la regulación del campo a los gremios y sindicatos. Es cierto que esta mirada se sustenta en un estudio en el contexto estadounidense, pero los procesos y mecanismos que describe la etnógrafa para analizar la objetividad como un ritual estratégico, corresponden precisamente a las continuidades de las normas y los valores profesionales que observamos en Chile después de 1970.

\section{CONTINUIDADES}

La ideología profesional del periodismo se rastrea, durante la Unidad Popular, en las continuidades del proceso de fabricación de los diarios, cuya principal función es distinguir entre opinión e información. Estas huellas se pueden observar en las mismas páginas de los diarios, en las formas y los textos periodísticos, lo que relativiza la hipótesis de la ideologización del periodismo y la ruptura de las rutinas periodísticas. El argumento recalca el profesionalismo del oficio de periodista al momento de la elección de Allende, la regulación y representación que no prohibía la opinión en los medios de comunicación, sino que la enmarcaba en formas y espacios mediáticos específicos. Esta repartición territorial de opinión e información en las páginas de los diarios no se desorganiza después de 1970. 
En su larga trayectoria en Chile, los medios de comunicación y el periodismo ya se habían transformado en varias oportunidades. En cada una de estas variaciones, que abarcan dimensiones tanto prácticas como tecnológicas, económicas y culturales, el rol social y político del periodismo en las relaciones de poder históricas, y la relación de los periodistas con la política, han cambiado. Durante el siglo XVIII, los publicistas de la Corona española trabajan en la circulación de la información oficial como apéndices de la Iglesia y la Administración Real. A raíz del proyecto republicano, los editores de diarios asumían un trabajo político y no se distinguían de los escritores, aunque estos no los asimilaban y trataban de levantar una frontera. La soberanía del Estado se ejercía con la persecución de los propietarios de diarios y sus editorialistas, al definir reglas legales y constitucionales sobre la libertad de prensa que entregaban protección a las élites, el honor y la reputación (Piwonka, 2000).

Ossandón y Santa Cruz (1998) observan una primera inflexión a finales del siglo XIX, a partir de la transformación que se estaba gestando desde hace unas décadas en diarios como El Ferrocaril, El Mercurio y El Diario Ilustrado. Los investigadores ponen luz sobre la manera en la que el oficio de periodista se objetivizó y se hegemonizó paulatinamente en la prensa chilena y sus páginas. Lo identifican precisamente en un decidido enfoque hacia lo noticioso, por sobre la opinión; el uso creciente del anonimato por los autores de estas notas informativas; y en el aumento de la propaganda comercial en las páginas de prensa. Los diarios funcionaban como "sujeto de enunciación", es decir, el título y la empresa se habían vuelto más importantes que los autores. Las narrativas periodísticas y los avisos comerciales ocupaban la mayoría del espacio de los diarios. "La noticia adquiere mayor importancia que los artículos de redacción y las editoriales" (Valdebenito, 1956: 66).

No significa que la opinión haya desaparecido de los diarios y periódicos chilenos, sino que pierde transversalidad en sus textos, y la prensa de partido sigue circulando al adoptar el modelo noticioso. Se sedimenta la opinión en espacios propios: la portada, las páginas de opinión y las páginas finales; y la línea editorial se expresa en la pauta de los diarios (las prioridades temáticas que se organizan en cuerpos y secciones). Son espacios que enmarcan los contenidos en las materialidades de la opinión (pueden ser en la misma cuadrícula, en las formas que toman los textos y mensajes —el dibujo, el uso de colores, tipografías, etcétera-). Tampoco desparece la opinión del sistema mediático, al favor de los diarios fundados al alba de un proyecto político —ya sea partidario, militante o activista-. No existe un resurgimiento propio de los mil días.

Las rutinas y la cultura profesional siguen controlando las conductas, los comportamientos y las aptitudes de los periodistas; y el desempeño pasa 
por la capacidad de rellenar el espacio del diario. En términos culturales, la profesionalización del oficio ha objetivado la figura del editorialista en la figura del periodista, cuya función consiste en regular el público como sujeto-objeto espacial de saber. En términos prácticos, esta regulación se activa en rutinas que dan una racionalidad al proceso de producción de las noticias (Stange y Salinas, 2009). De manera clásica, estas rutinas se organizaban, en el Chile entre los años 1950 y 1970, según plazos predeterminados que daban garantía de que al final del día el diario estaría rellenado de noticias. A lo largo de este proceso, varias instancias, a la vez colectivas e individuales, funcionaban como filtros: la reunión de pauta y la misma pauta del diario, las relaciones con las fuentes, el reporteo, la diagramación, la edición y la titulación. El periodista se sustentaba, en definitiva, en la figura del guardabarrera que filtra por plazos.

Afirmamos aquí la continuidad de esta figura y de las normas del periodismo profesional durante la UP. Los criterios para seleccionar y jerarquizar una noticia siguen sin mayor modificación, y los diarios mantienen una frontera entre información y opinión, como lo pone en evidencia la organización espacial de sus páginas. La pauta de los diarios no rompe ni la cuadrícula se descuadra. En sus testimonios, los periodistas visibilizan solidaridades profesionales que trascienden el posicionamiento político y/o editorial, y apelan a la solidaridad profesional. El Mercurio cuenta con una importante sección en la Asamblea de los Periodistas de Izquierda (1971). Un entrevistado testifica que, ante una noticia de último minuto, llamaba a su par de El Mercurio "aunque era de derecha" (Faure, 2014).

Durante la UP, la lectura de los diarios estaba ciertamente condicionada por la portada, ya sea por la morfología clásica de la prensa o porque la principal práctica de consumo de medios consiste en consultar los títulos exhibidos alrededor de los kioscos, en cada esquina de las calles chilenas. Las primeras páginas interiores incluían, generalmente, las columnas de opinión y las secciones editoriales (caricaturas, textos paródicos, etcétera). La línea editorial de la prensa aparecía también en sus últimas páginas cuando eran de reportaje (hasta cuatro páginas el domingo, en El Siglo y El Mercurio). Si bien el argumento clásico sobre la ideologización y la polarización de los medios de comunicación chilenos durante la UP se sostiene sobre el estudio de las portadas y las páginas de opinión, una vez que se revisan las páginas interiores, se leen notas que remitían más bien a un periodismo informativo o interpretativo.

Reducir el análisis a los títulos y las portadas oscurece la complejidad del trabajo periodístico durante la UP. Para tener una visión completa de los diarios hace falta observar sus pautas. La organización temática mantenía continuidad hasta en los cambios de pauta producto de eventos rituales y rutinarios (Te Deum o 21 de mayo). Con un afán sintético y esquemático, se puede señalar que las secuencias temáticas de los periódicos estudiados seguían este orden: Opinión, Política y 
Sociedad, Policiales, Internacional, Cultura y Espectáculo, Deportes. La variación del espacio de esas secciones muestra, sin embargo, las distintas prioridades de cada línea editorial, lo que contribuía, ciertamente, a la enunciación de preocupaciones políticas. Por ejemplo, se hace visible una preocupación por el sindicalismo en El Siglo, mientras en El Mercurio había más lugar para la economía; la prensa tabloide, por su parte, dedicaba más espacio a la sección policial y a la de deportes.

No obstante, la separación espacial entre opinión e información no se desestructuraba, como tampoco se esparcía la línea editorial en otras de las páginas de los diarios no convencionalmente asignadas para esos contenidos. Las rutinas seguían seleccionando y jerarquizando las noticias espacialmente, para ganar en eficiencia en la fabricación del producto mediático y dar legitimidad a los periodistas y las empresas mediáticas. Se regulaban los problemas discutidos en el espacio mediático según criterios espaciales de noticiabilidad. El dispositivo central para cumplir con esta tarea eran, sin duda, los plazos de las distintas etapas de fabricación del diario, que estructuraban este proceso y seguían las mismas lógicas rutinarias.

La tarea central del periodista consistía en ordenar cada noticia y la pauta del diario, según una lógica espacial: lo más importante tiene que aparecer primero, ya sea en el diario, en cada página o en cada nota (poco importa su extensión o su género periodístico). En sus testimonios, los/as mismos/as periodistas explican cómo este rol se socializa al aprender la cotidianeidad de las salas de redacción y, en específico, las reglas del juego de la reunión de pauta, que planifica y anticipa la cuadrícula de los diarios. Otros/as, que han seguido una formación universitaria, relatan cómo se les enseñaba este mismo rol al trabajar la pirámide invertida y la identificación de lo noticiable en la universidad (Cabrera Ferrada, 1994). De esta manera, se forma el rol que consiste en llenar el diario y canalizar el flujo de noticias, es decir, la figura clásica del guardabarrera.

Las señales materiales de la progresiva objetivización del periodismo se acompañaban de intentos de autonomización profesional, en un proceso contemporáneo al resto de América Latina, que pasa por los trabajos de organización de un saber-hacer, de consolidación cultural y de negociación institucional con el Estado. Este proyecto se fortaleció durante la década de 1940 en torno a Juan Emilio Pacull y Lenka Franulic, promoviendo la apertura de las primeras escuelas de periodismo (1953), la constitución del Colegio de Periodistas de Chile (1956), la publicación de los primeros manuales de periodismo escritos por colegas nacionales (Cortéz, 1956) y el recrudecimiento de las historias del periodismo (Valdebenito, 1956). Tal como lo observa el historiador Nerone (2011) en el caso estadounidense, la historia del periodismo se consolida en Chile para legitimar las formaciones universitarias, además, agregamos, de arraigar la autonomización profesional. 
Las instancias gremiales obtienen la posibilidad de regular las fronteras del campo periodístico, es decir, los mecanismos para incluir a los profesionales y excluirlos de la comunidad gremial ${ }^{2}$. Al reconocer la especificidad social del periodismo, el Estado chileno otorgó la regulación de esta autonomía a los periodistas profesionales a cambio de un autocontrol ético activado bajo la idea de "responsabilidad social". Se fundamenta, para los periodistas, a partir de una misión de información a los ciudadanos, que tienen derecho a acceder a noticias de calidad, libres y pluralistas. Esta es la responsabilidad democrática a la que se compromete el gremio a cambio de la garantía estatal del derecho a informar, así como de mecanismos de protección social propios de la profesión. Estos mecanismos generan una identificación profesional, tal como se rastrea en una encuesta de 1967 sobre la relación de los periodistas con la idea misma de profesión: el fuerte sentimiento de pertenencia a una comunidad que se autonomizó y se regula (Menanteau-Horta, 1967).

Este proceso se sigue desarrollando durante los mil días de Allende. El Estatuto de Garantías Constitucionales refleja esta concepción de un periodismo socialmente responsable. Y las pocas intervenciones políticas y judiciales en contra de los medios, no obstante el agudo conflicto político, generalmente responden a demandas por contenidos injuriosos y desmesurados (Tupper, 2004). Se aprueba una serie de siete leyes que buscan consolidar la protección social de la profesión de periodista, y reconocen su especificidad social. Además, el gremio sigue activo y, a partir de la revisión de las actas del Colegio de Periodistas entre 1964 y 1973, no se puede confirmar que haya un sesgo político en los juicios del Tribunal de Ética o en las orientaciones que toma la instancia de representación colectiva. Política hay en la competencia por la representación gremial, en la creación de diarios propiamente políticos, en la radicalización de las páginas de opinión; pero esta politización no ataca el pacto social sobre las especificidades profesionales del periodismo.

La continuidad de las rutinas periodísticas también se mantiene después de 1973, aunque las condiciones de pluralismo y el ejercicio de la profesión sean directamente amenazados por el ejercicio soberano del poder estatal de parte de la Junta Militar. Hemos evidenciado que se mantiene la misma racionalidad burocrática para producir las noticias en la relación con las fuentes, el trabajo informativo y la pauta de los diarios chilenos (Faure, Salinas y Stange, 2013).

En síntesis, al investigar el periodismo durante la UP se reconoce empíricamente la dicotomía liberal clásica entre opinión e información. Las rutinas profesionales

2. Nos referimos a la formación universitaria, la tarjeta de periodismo, el arancel y el Tribunal de Ética. 
del periodismo chileno, que funcionaban a partir de la repartición de la noticiabilidad en el espacio y un proceso construido sobre plazos progresivos, muestran una continuidad con el proceso de mercantilización del sistema mediático y profesionalización del periodismo, que operó desde inicios del siglo XX. Los periodistas chilenos no ceden a la radicalización política ni tampoco dejan de lado los valores y las normas del profesionalismo y la responsabilidad social, negociados arduamente con la autonomía profesional desde la década de 1950. Sin embargo, el estudio del periodismo durante la UP revela otras discontinuidades que, si bien no son ideológicas, muestran cómo el conflicto político afecta el ejercicio del periodismo profesional. A partir de 1972, la presión de los acontecimientos políticos impacta en la distribución del espacio de las publicaciones periodísticas y, en consecuencia, en la organización de los plazos de filtrado de las noticias.

\section{PRIORIDADES}

Al agudizarse el conflicto político durante el gobierno de Allende, los textos periodísticos no se ideologizan mecánicamente, más bien se desorganizan las rutinas por la presión temporal que impone el conflicto. Estas distorsiones permiten comprender, a nuestro juicio, la mutación del periodismo chileno en la historia reciente, es decir, desde una función de filtrado a una de catalización de noticias. Si se observan las temporalidades de las rutinas periodísticas durante los mil días, se vislumbran los gérmenes de una transformación en la temporalidad profesional.

El flujo de hechos y acontecimientos se dilató durante la UP, sin duda, a causa de la tensión propia de la crisis política. Esta tendencia se observa en el trabajo de memoria, los estudios sobre los mil días y los numerosos libros, documentales o películas sobre el periodo. Cada producto evoca nuevas fechas, otros puntos de vista o propone otras lecturas de acontecimientos que ya están saturados de sentido. Pareciera que los eventos que marcaron los mil días son inagotables, hasta cincuenta años después. El relato histórico recuerda la frecuencia de las decisiones; la cadencia política y la rítmica del conflicto social. Esto lo pone en evidencia un ejemplo simbólico: la cantidad anual de huelgas pasó de 977 en 1969 a 3.652 en 1973 (Marini, 1976: 152).

En ese contexto, la prensa y los medios de comunicación tuvieron un cierto éxito. Las audiencias fueron las más altas de la historia chilena: con 7.884.768 habitantes, se compraron casi 850.000 diarios cada día (Santa Cruz, 1988). El mercado mediático contó con numerosas publicaciones y medios de comunicación que seguían creándose; por ejemplo, los semanales de la Editorial Quimantú. En sus páginas, los diarios difundieron cada día noticias en un volumen considerado como el más elevado de la historia de la prensa chilena. Se publicaba un promedio de 106 
notas por diario en 1971, y este volumen aumentó hasta alcanzar la publicación de 132 noticias diarias en promedio en 1973. Este dato cuantitativo bien corrobora la presión de los acontecimientos sobre el cotidiano periodístico durante la UP.

En términos tecnológicos, los medios de difusión no cambiaron, pero una “innovación" potenció esa presión de los eventos, con la importación en 1971 de la primera rotativa offset del país en la Sociedad Imprenta Horizonte, del Partido Comunista de Chile. Esa tecnología reestructuró las etapas del ciclo de producción, permitió un aumento de la paginación (que no ocurrirá) y una estandarización de las pautas. Favoreció también el uso de ilustraciones visuales. Por lo tanto, se abrieron nuevas posibilidades temporales en el ciclo de producción de los diarios y en la gestión de su espacio, considerando además que Horizonte fue la sociedad impresora de varias publicaciones entre 1970 y 1973 (El Siglo, Las Noticias de Última Hora, Puro Chile, Quinta Rueda, entre otras).

Entre estas nuevas posibilidades tecnológicas y la crisis política, se aceleró el tiempo mediático y se multiplicaron los plazos de publicación. La diversificación de los vespertinos ofreció a los periodistas la posibilidad de tomar en cuenta lo que escribieran sus pares, y los lectores tuvieron más posibilidades de informarse. Las cifras de escucha de radio muestran un consumo de información alto y que la presión de la crisis aumentó el volumen y el ritmo del flujo de noticias. La televisión también contribuyó a esa abundancia a través del aumento continuo de los espectadores y de la programación diaria: en 1963 se registraron 35.000 televisores en el territorio chileno y en 1967 más de 55.000, jllegando a los 300.000 en 1970! (Mattelart, Mattelart, Piccini, 1970: 72). El tiempo de transmisión también se extendió hasta unas 10 horas diarias en 1973.

Los cables de agencia se usan de manera amplia, lo que agrega presión temporal sobre las salas de redacción. Si bien estos cables respondían a lógicas políticas (El Siglo privilegia Tass, cuando ElMercurio publica AFP o AO; y la organización misma de los cables era sujeta a intervención, cf. Alvear y Lugo-Ocando, 2016), esta rutina muestra una paradoja temporal: entre la continuidad del flujo de noticias y el carácter cada vez más efímero de las informaciones incluidas en cada cable. El servicio que proponen las agencias garantizaba un flujo inmediato, permanente y abundante de noticias a las salas de redacción en base a la fe en el testimonio periodístico. Y favoreció la masificación del mercado mediático, objetivando lo noticioso en lo novedoso.

Todo esto contribuyó a incrementar la sensación de rapidez, abundancia y permanencia del flujo noticioso. Y esos cambios temporales modificaron el sentido de la reactividad mediática que, de la inmediatez del día después, pasó a ser un principio del proceso continuo e ininterrumpido de producción de información. A través de esa intensificación del trabajo periodístico y en un conflicto político 
acelerado, las noticias perdieron valor temporal y, por tanto, económico y social. Se volvieron altamente perecederas, desde las lógicas de contenido siempre nuevo o "fresco".

En esta configuración, se disputa la organización espacial de las rutinas periodísticas que operaba en Chile hasta aquel entonces. Se observa en la prensa liberal tradicional, lo que da más fuerza aun al argumento. El Mercurio rompió con la tradición liberal en dos oportunidades, a través de un cambio de diagramación y la distribución de los contenidos de su portada. Estos dos hitos periodísticos, del 15 de junio y el 5 de septiembre 1973, ejemplifican las luchas espaciales a las que estuvieron sujetas las normas de la profesión que el propio El Mercurio había contribuido a instalar, consolidar y enjambrar. La selección y jerarquización de las noticias para representar la línea editorial del diario se había reducido a lo mínimo.

Los desajustes de diagramación en las páginas de los diarios muestran también que se priorizó cada día más el volumen y el ritmo del flujo de noticias sobre la selección de los hechos (la función de filtro). Esas dificultades se hacen visibles en la relativa desorganización espacial de los diarios, donde aparecieron ajustes y excepciones formales cada día con más frecuencia. La cuadrícula de los diarios sigue existiendo (nunca desaparecerá), pero se desordena: ciertas columnas desbordaban el bloqueartículo adyacente, y se publicaban muchas noticias blandas, es decir, noticias cortas y breves con apenas una fuente, que no benefician un trabajo de enfatización (a partir de 1972, la cantidad de fuentes por nota baja a 1,05 en promedio). Esos ajustes muestran los intentos de adaptarse a la urgencia mediática y a la densidad del flujo de noticias, a pesar de la estabilidad del espacio de publicación.

El contexto de fuerte competencia comercial y política aceleró la reactividad periodística, multiplicando las posibilidades de tomar en cuenta a los pares. De hecho, incluso los/as entrevistados/as lo destacan al momento de recordar el ejercicio cotidiano del oficio entre 1970 y 1973. Existe una "carrera" por la noticia, para la que las materialidades de los diarios incluso pudieron constituir un obstáculo. La paginación se mantuvo estable, oscilando entre 12 y 48 páginas según el diario, y no se constatan cambios entre 1970 y 1973. Las principales variaciones se identifican en el día domingo (día en que los diarios eran tradicionalmente más voluminosos) o en la navidad (los anuncios comerciales disputaban el espacio de publicación de manera intensa). Los criterios de la redacción no ganaron espacio, lo que no facilitó la función de guardabarrera y el funcionamiento de los plazos para operar el filtro de selección y jerarquización de los hechos. Al contrario, la crisis política engendró nuevas precauciones periodísticas, de alcance temporal. Por ejemplo, recibimos el testimonio de que, en Clarín, se postergó el plazo de la sección política y se disputaba el espacio y el territorio de los avisos comerciales para expender las páginas informativas. 
Durante la Unidad Popular, la vida de una noticia se fragmentó según la programación del medio de comunicación, es decir, un día para un diario o una hora para un noticiero televisivo. El carácter mercantil de la noticia obligó a la reactividad, puesto que la difusión solo tiene valor cuando la noticia desaparece y revela la atención que ha producido en las audiencias. Así, la noticiabilidad no solo consistió en fabricar una noticia según las normas profesionales, además residió en realizar este ideal en el menor plazo posible para retener la atención de los consumidores y movilizar a los militantes. A mayor distancia temporal de la noticia con el evento que relataba, menor su valor periodístico. Poco importaban los intervalos institucionales y/o tecnológicos entre dos momentos de publicación, el ritmo mediático los equiparaba a un proceso rápido, que toma valor por el desvanecimiento de las noticias en la velocidad de los mismos plazos de producción y en la atención que engendraban. En consecuencia, y en términos teóricos, el evento mismo de la enunciación se ha homogeneizado y se neutraliza poco a poco con lo efímero de las noticias, en un flujo abundante, permanente y frecuente. La reactividad periodística cambió de sentido durante la Unidad Popular, y consistió entonces en ganar tiempo y tener la capacidad de reaccionar a los cambios del entorno.

Esta presión temporal y la disputa por el orden espacial del periodismo profesional también se lee en el proceso de fabricación de medios alternativos que apuntaban a dar voz a los "sin voz", y que experimentaban las formas periodísticas con las clases más populares. Estas críticas, contraprácticas y contraconductas espaciales se pueden rastrear en los programas de investigación y sus usos, así como en experiencias mediáticas territoriales.

En términos académicos, la problemática de los aparatos ideológicos se formula en los numerosos textos que buscaban identificar la ideología de los medios de masas y el enfoque ampliamente privilegiado es la teoría de la dependencia. Generó todo un trabajo de investigación y acción sobre los textos periodísticos, específicamente en el marco de la oficina de investigación y evaluación de las comunicaciones de masas de la Editorial Quimantú. Michèle y Armand Mattelart formaban parte de los académicos que colaboraban con este servicio e implementaban talleres populares con trabajadores, donde buscaban formas inéditas de comunicación acordes con formas también inéditas de organización (Mattelart, 1974).

Buena parte del experimento se desarrolló a partir de entrevistas y observaciones participantes con sesiones de lectura de obreros, pobladores y campesinos, y consideraba el contenido de los diarios no solo como mensaje, sino también como forma en su espacialidad. Así, participantes del experimento testifican que se consideraban y estudiaban los cambios de pauta o tipográficos para ayudar a la lectura. En un momento en que el papel y el volumen del diario eran las variables 
primordiales para publicar, este proyecto bien muestra que el espacio constituía un campo de batalla mediático en el proceso de producción de masas organizadas y de lo que llamaban los "públicos reformados" (Mattelart, 1974), capaces de desmitificar las estructuras semánticas de dominación y el sistema de representación del mundo.

Esta disputa contra la objetividad del espacio se confirma en las experimentaciones mediáticas durante la UP. A tal punto, que una parte de las propuestas y "resistencias" mediáticas de la esfera pública plebeya (aparecida con el cambio de siglo, cf. Santa Cruz, 1988) consistía en proponer publicaciones desorganizadas en términos espaciales y que no seguían una frecuencia de publicación identificable. Estas experiencias muestran la intención de salir de los ciclos de producción de las noticias (además de un cierto antiprofesionalismo y del uso de fuentes alternativas). El fenómeno se observa con mucha claridad en la explosión de folletos y boletines de los cordones industriales (por ejemplo, Nueva Habana). También en la prensa alternativa como Surazo (Concepción) o Mañanita (Talca), diarios que nacieron de las luchas lideradas por periodistas profesionales y ponían en tela de juicio el trabajo de selección de las noticias al citar otras voces en los diarios o dejándoles espacio para vehiculizar sus opiniones. Todas esas publicaciones experimentaron con las formas visuales y los códigos del periodismo profesional, con el tamaño de los textos y siguieron una diagramación más creativa que no calza con la cuadrícula clásica.

Entre la diversidad de voces incluidas y la creatividad formal, la mediación del guardabarrera quedó truncada. Esa función y sus valores clásicos fueron cuestionados, por ejemplo, durante la Asamblea Nacional de Periodistas de Izquierda (abril de 1971), agrupación que, como su nombre lo indica, apuntaba a defender el periodismo comprometido. Este trabajo de contrainformación operó al cuestionar la administración espacial de la noticiabilidad y al hacerla objeto de un conflicto interno del campo.

El dispositivo de plazos terminó desarreglándose. La aceleración de los acontecimientos, la presión del mismo sistema mediático, los ajustes prácticos, las derivas, las críticas, las contraprácticas y las contraconductas muestran que la espacialidad de las rutinas profesionales ha sido superada, interrogada e invertida. Los periodistas tuvieron que adaptar su quehacer cotidiano para captar la mayor parte de los eventos, lo que redujo la rigidez de la cuadrícula de los diarios, el trabajo de selección de las noticias y la figura discursiva del guardabarrera. Pero, para afirmar que la reactividad periodística cambia de sentido, hace falta seguir indagando del otro lado del golpe de Estado, para saber si la lógica del flujo sigue por encima del trabajo de selección de las noticias. En otras palabras, para observar si la lógica de circulación del flujo mediático ordena paulatinamente el quehacer periodístico.

La tendencia pareciera mostrar que esta nueva prioridad profesional se consolida durante la dictadura debido a las condiciones limitadas de pluralismo, que darían 
continuidad a la transformación del sentido de noticiabilidad que observamos durante la Unidad Popular. La profesión busca garantizar las condiciones de su ejercicio, nutriendo prioritariamente la circulación de las noticias a costa de la capacidad de seleccionar y jerarquizar la información (sometida a censura), bajo el control unilateral de la Junta Militar, la Dinacos y el aparato de inteligencia y represión (DINA y CNI), produciéndose autocensura.

\section{APERTURA(S)}

Durante la UP, entonces, no asistimos a una regresión de la prensa hacia sus primeros pasos, es decir, hacia una batalla editorial monopolística y transversal a la esfera pública burguesa. Al contrario, vemos el conflicto entre distintas maneras de concebir la "ideología", partidista, burguesa o profesional. Después de reconstruir las rutinas periodísticas del momento, observamos que la función de guardabarrera, que se había instalado con la mercantilización de la prensa, la racionalización de las empresas periodísticas y la profesionalización del oficio, no se desvaneció entre 1970 y 1972. Al contrario, trató de resistir a la presión de la crisis política.

Si bien el periodismo liberal se mantiene vigente durante la crisis política gracias a prácticas institucionalizadas que siguen tratando de manejar lo imprevisto a partir de un trabajo de repartición espacial, las resistencias o contraprácticas que emergieron disputan la misma regulación especial de la objetividad periodística. Estas resistencias al profesionalismo periodístico son potenciadas por la urgencia política y la aceleración de las temporalidades. La presión de los eventos catalizó el flujo de noticias y distorsionó el quehacer periodístico en clave temporal. Los criterios que administraban la importancia periodística mostraron dificultades frente al flujo dilatado de noticias.

En términos históricos, la figura del "guardabarrera" no se desvanece debido a la ideologización de la sociedad chilena, sino que se (re)articula según otra prioridad: nutrir un flujo de noticias voluminoso y acelerado. En términos periodísticos, la Unidad Popular es el momento en el que, bajo la presión de los eventos cotidianos, se desajustan las rutinas profesionales para (re)ordenarse según otra temporalidad. Según esta hipótesis, el golpe de Estado no es el resultado de la ideologización de la prensa ni tampoco una ruptura en la historia del periodismo. Al contrario, las condiciones limitadas del pluralismo consolidarían un nuevo orden de prioridades en el ejercicio de la profesión, orientado a la circulación del flujo de noticias antes que a su filtro. Es a raíz de esta nueva prioridad que se justifica, históricamente, la uniformidad temática, los encuadres deslegitimadores de toda iniciativa de cambio, las fuentes unívocas y oficiales que las mismas movilizaciones sociales denuncian hoy día, coincidiendo con numerosos estudios de los medios en Chile. 


\section{REFERENCIAS}

Ahumada, P. (2017). "Del mercado de las ideas a la mercantilización de la esfera pública”. Derecho y Crítica Social, 3(2): 151-189. Disponible en: https:// derechoycriticasocial.files.wordpress.com/2018/02/ahumada-dcs.pdf

Alvear, F. J., y Lugo-Ocando, J. (2016). "When Geopolitics become Moral Panic". El Mercurio and the use of international news as propaganda against Salvador Allende's Chile (1970-1973)". Media History, 24(3-4): 528-546. Disponible en: https://doi.org/10.1080/13688804.2016.1211929

Baltra, L. (2012). La prensa chilena encrucijada. Santiago: LOM Ediciones.

Bernedo, P. (2003). "La prensa escrita durante la Unidad Popular". En Rolle, C. (ed.). 1973: La vida cotidiana en un año crucial, Santiago de Chile: Planeta, pp. $59-95$.

Bernedo, P., y Porath, W. (2004). "A tres décadas del golpe: ¿Cómo contribuyó la prensa al quiebre de la democracia chilena?". Cuadernos de Información, 16: 114-124. Disponible en: https://cuadernos.info/index.php/CDI/article/ view $/ 168$

BREED, W. (1955). "Social control in the Newsroom: A Functional Analysis". Social Forces, 33(4): 326-355.

CABRera Ferrada, A. (1994). Los vencedores del sol: reportaje a creadores de y protagonistas de los primeros dieciséis años de vida de la primera Escuela Universitaria de Periodismo de Chile 1953-1968. Madrid: Pays Ltda.

CÁrdenas, J. P. (2005). "Periodistas, conflictos sociales y reconciliación". Revista Comunicación y Medios, 16. Disponible en: http://www.revistas.uchile.cl/index. $\mathrm{php} / \mathrm{RCM} /$ article/viewFile/11567/11925.

Catalán, E. (1967). La propaganda: instrumento de presión política. Santiago: Universidad de Chile, Escuela de Periodismo, $2^{\mathrm{a}}$ ed.

Dooner, P. (1989). Periodismo y politica: la prensa en Chile 1970-1973. Santiago: Editorial Andante - Hoy Ediciones.

DuRÁn, C. (1994 [1973]). El Mercurio: ideología y propaganda 1954-1994. Ensayos de interpretación bilógica y psico-histórica. Ensayo 1: propaganda de agitación en el periodo agosto 1972 - marzo 1973. Santiago: Ediciones Chileamérica - Cesoc.

FADDEn, P. (1974). "The Media in Allende's Chile", Journal of Communication, 24(1): $59-70$. 
FAure, A. (2014). (Des) Ordres journalistiques durant une crise revolutionnaire. Chroniques de l'être journalistique chilien durant l'Unité Populaire (1970-1973). Grenoble: Sciences Po Grenoble, Tomo 2. Disponible en: http://www.theses.fr/s97161

Faure, A., Salinas, C., y Stange, H. (2013). "The dominance of common sense: the influence of the media system on professional practices of journalists, 1970-2000”. En Puppis, M., Künzer, M. y Jarren, O. (eds.), Media Structures and Media Performances. Zurich: OAW, pp. 283-301.

Gans, H. (1980). Deciding What's News. A Study of CBS Evening News, NBC Nightly News, Newsweek and Time. Nueva York: First Vintage Books Editions.

Joignant, A. (2012). "Sens, masse et puissance. Dégradations cérémonielles et représentations de la puissance sous l'Unité populaire au Chili (1970-1973)". En Sommier, I. y Criettez, X. (eds.), Les dimensions émotionnelles du politique. Chemin de traverse avec Philippe Braud. París, Presses universitaires de Rennes, pp. 131-142.

Lagos, R. (1962). La concentración del poder económico: su teoría, realidad chilena. Santiago: Editorial del Pacífico.

Mac Hale, T. (1972). El Frente de la Libertad de Expresión: 1970-1972. Santiago: Portada.

Mattelart, A., y Mattelart, M. (1972). "Ruptura y continuidad en la comunicación: puntos para una polémica”, Cuadernos de Realidad Nacional, 12: 100-144.

Mattelart, A. (1974). Mass media, idéologie et mouvement révolutionnaire: Chili 19701973. París: Anthropos.

Mattelart, A., Mattelart, M., y Piccini, M. (1970). "Los medios de comunicación de masa. La ideología de la prensa liberal en Chile", Cuadernos de la Realidad Nacional, 3 .

Menanteau-Horta, D. (1967). "Professionalism of Journalists in Santiago of Chile". Journal and Mass Communication Quarterly, 44: 715-724. Disponible en: 10.1177/107769906704400413

Navarro Ceardi, A. (5 de noviembre, 2013). "La prensa chilena en tiempo de Cólera”. Disponible en: http://arturo-navarro.blogspot.fr/2013/11/laprensa-chilena-en-tiempos-de-colera.html

Nerone, J. (2011). "Does Journalism History Matters?". American Journalism Historians Association, 28, 7-27. Disponible en: https:/ /www.tandfonline.com/ doi/abs/10.1080/08821127.2011.10677800\#.UjiDomR4b-Q 
Ossandón B., C., y SANTA Cruz A., E. (1998). Entre las alas y el plomo. La gestación de la prensa moderna en Chile. Santiago de Chile: Universidad Arcis - LOM Ediciones.

Portales, D. (1983). "El movimiento popular y las comunicaciones: reflexiones a partir de la experiencia chilena". En Reyes MatTA, F. (ed.). Comunicación Alternativa y Búsquedas Democráticas, México D. F.: ILET, pp. 59-69.

Rivera, C. (2008). "La verdad está en los hechos: una tensión entre objetividad y oposición. Radio Cooperativa en dictadura". Historia. 41(1): 79-98. Disponible en: https:// scielo.conicyt.cl/pdf/historia/v41n1/art04.pdf

(2015). "Diálogos y reflexiones sobre las comunicaciones en la Unidad Popular: Chile, 1970-1973". Historia y Comunicación Social. 20(2): 345-367. Disponible en: https://doi.org/10.5209/rev_HICS.2015.v20.n2.51388

Rojo de la Rosa, J. (1976). "Manipulación de información y conflicto ideológico: Chile 1970-1973”. Nueva Sociedad, 25, 1976, 66-77. Disponible en: https:// nuso.org/articulo/manipulacion-de-informacion-y-conflicto-ideologicochile-1970-1973/

Stange, H., y Salinas, C. (2009). "Rutinas periodísticas. Discusión y trayectos teóricos sobre el concepto y su estudio en la prensa chilena", Cuadernos de Trabajo del ICEI, Santiago: Universidad de Chile, CECOM.

Santa Cruz, E. (1988). Análisis histórico del periodismo chileno. Santiago: Nuestra América Ediciones.

Shoemaker, P. y ReESe, S. (1991). Mediating the message: theories of influence on mass media content. New York: Longman.

Sunkel, G. (1985). Razón y Pasión en la Prensa Popular. Un Estudio sobre Cultura Popular, Cultura de Masas y Cultura Política. Santiago de Chile: Estudios ILET.

Taufic, C. (2012 [1971]). Periodismo y lucha de clases. Madrid: Akal, "Básicos del Bolsillo", $2^{\mathrm{a}}$ ed.

Tironi, E., y Sunkel, G. (1993). "Modernización de las comunicaciones y democratización de la política. Los medios en la transición a la democracia en Chile”. Estudios Públicos, 52: 215-246. Disponible en: https://www. cepchile.cl/cep/estudios-publicos/n-31-a-la-60/estudios-publicos-n-52/ modernizacion-de-las-comunicaciones-y-democratizacion-de-la-politica

Tuchman, G. (1978). Making News. A study in the construction of reality. New York: Free Press.

Tupper, P. (2004). Allende, la cible. Des média chiliens et de la CIA (1970-1973). París: Editions de L'Amandiers. 
Uribe, H. (1996). "Prensa y periodismo político en los años 1960/70". En: Carmona, E. (ed.) Morir es la noticia. Santiago de Chile: Ernesto Carmona Editor. Disponible en: http://www.derechos.org/nizkor/chile/libros/ reporter/capI02.html

Valdebenito, A. (1956). Historia del Periodismo Chileno. Santiago: Imprenta Fantasía y Colegio de Periodistas.

Wolf, M. (1997). “Los emisores de noticias en la investigación sobre comunicación”. Revista Zer, 3: 9-14. Disponible en: http://www.ehu.eus/zer/hemeroteca/ pdfs/zer03-01-wolf.pdf 